\title{
QUALITY OF LIFE, PERSON-CENTRED CARE AND LIVED EXPERIENCES OF NURSING HOME RESIDENTS IN A DEVELOPED URBAN ASIAN COUNTRY: A CROSS-SECTIONAL STUDY
}

\author{
C.W. TEW ${ }^{1,2}$, S.P. ONG ${ }^{2}{ }^{*}$, P.L.K. YAP ${ }^{1,2}$, A.Y.C. LIM ${ }^{2}$, N. LUO ${ }^{3}$, G.C.H. KOH ${ }^{3}$, T.P. NG ${ }^{2,4}$, S.L. WEE2,5,6 \\ 1. Department of Geriatric Medicine. Khoo Teck Puat Hospital, Singapore; 2. Geriatric Education and Research Institute, Singapore; 3. Saw Swee Hock School of Public Health, \\ National University of Singapore. Singapore; 4. Gerontological Research Programme, Department of Psychological Medicine, Yong Loo Lin School of Medicine, National University \\ of Singapore. Singapore; 5. Health and Social Sciences Cluster, Singapore Institute of Technology, Singapore; 6. Program of Health Services and System Research, Duke-National \\ University of Singapore Graduate Medical School;Singapore.* Joint first authors. Corresponding author: Shiou Liang Wee, PhD, Geriatric Education and Research Institute, 2 Yishun \\ Central 2, Singapore 768024, Tel: 65-68078011. Email: weeshiouliang@gmail.com; Philip Lin Kiat Yap, Department of Geriatric Medicine, Khoo Teck Puat Hospital, 90 Yishun Central, \\ Singapore 768828, Tel: 65-66022154. Email: yap.philip.lk@ktph.com.sg
}

\begin{abstract}
Background: Literature emphasises the benefits of person-centred approaches in nursing homes. Objectives: To describe the quality of life, well/ill being and person-centred care of residents, and explore relationship between person-centred care and well/ill being in 7 nursing homes. Design: A cross-sectional study. Setting: Seven nursing homes of different built period and design typologies in Singapore. Participants: 696 nursing home residents. Measurements: Measures used were EQ-5D for quality of life, Dementia Care Mapping for well/ill being, Resident Satisfaction Score and Person-Directed Dementia Care Assessment Tool as measure of person-centred care. Results: Mean EQ-5D-5L index was 0.096 ( $\mathrm{SD}=0.45)$. Most residents had at least moderate problems in mobility $(66.5 \%)$, self-care $(63.6 \%)$ and usual activities $(63.0 \%)$. Mean well/ill being score was $1.69(\mathrm{SD}=0.98)$. A state of neutrality $(\mathrm{WIB}=+1)(48 \%)$ was most observed, followed by wellbeing (WIB $>+1)(29 \%)$ and ill-being (WIB<+1) $(6 \%)$. High positive potential behaviors were recorded $37 \%$ of the time, while low/no positive potential behaviors amount to $39 \%$. The overall resident satisfaction score was $3.43 / 5$ with borderline satisfaction with environment, food and activities, and low satisfaction with lifestyle and quality of interaction. The overall level of person-centred care was modest 2.3/4. Activities scored highest while the weakest domain was Environment. The overall level of person-centred care was positively correlated with resident well/ill being score $(\mathrm{F}=4.43, \mathrm{p}<0.001)$. Conclusions: A higher level of person-centred care is associated with better resident well-being. Beyond their physical and custodial needs, the residents' psychosocial needs can be better fulfilled. The areas of person-centred care amenable to improvement relate to environment, staff knowledge and training. These findings can inform resident care planning, policy development, and future research to support nursing homes in their endeavour to move towards more holistic and person-centric care.
\end{abstract}

Key words: Quality of life, person-centred care, lived experiences, nursing home, person-directed care.

Abbreviations: NH: nursing home; ADA: Alzheimer's Disease Association; QoL: quality of life; BCC: behavioural category codes; PCC: person-centred care; WIB: well/ill being; RSS: resident satisfaction survey; ME: mood and engagement; RAF: resident assessment form; PE: personal enhancers; ADL: activities of daily living; PD: personal detractors; DCM: dementia care mapping; PDDCAT: person-directed dementia care assessment tool.

\section{Introduction}

Asia-Pacific population is ageing rapidly. Its population proportion aged 60 years and above is projected to rise from $15 \%$ currently to more than $25 \%$ (1.3 billion) in 2050 (1). Among the countries, Singapore is one of the most rapidly aging nation, having transitioned from an aging to an aged society in 19 years. By 2050 , it is projected that more than $20 \%$ of its population will be aged 65 years and above, making it a 'super-aged' society (2).

When older people develop functional dependence, family members usually become care providers as the preference is for Asian elders to remain at home (3). However, declining birth rates and employment-related migration meant that this reliance on family members is becoming less viable. Thus, the shift towards formal residential long-term care as a more pragmatic solution. This growing demand was recognised in the well-regarded Singapore Healthcare Master Plan $2020(4,5)$. As a part of its comprehensive plan for its aging population, Singapore aimed to increase the number of nursing homes (NH) in Singapore by two to three annually to provide additional 1000 beds each year, thereby increasing the bed number from 8,800 in 2011 to 17,000 in 2020 (6).

WHO defined healthy aging as a "process of maintaining the functional ability that enables well-being in older age" (7). NHs must provide a supportive care environment to maximise their residents' well-being even with their physical limitations. This called for a paradigm shift of $\mathrm{NH}$ care from the medical and institution-based approach to a person-centric one (8). One which goes beyond assisting the residents with their disabilities to providing continued opportunities for autonomy, connectedness, meaning and joy. This more humanistic 


\section{EXTENT OF PERSON-CENTRED CARE IN ASIAN NURSING HOMES}

approach can close the gap between lower life quality reported in $\mathrm{NH}$ residents compared to their home-dwelling counterparts (9).

The quality of life (QoL) among NH residents in Asia has been reported. A study of six NHs in Singapore reported that the residents rated their QoL only modestly and more than $30 \%$ voiced dissatisfaction over not having their preference in routines and food respected (10). Qualitative studies of NHs in neighbouring Asian countries echo the residents' dissatisfaction with the highly institution-centred life, restricted activities, distancing relationships, inability to maintain previous lifestyles and lack individualized care $(11,12)$.

In keeping with the older people's wish to receive care in a humanistic and nurturing environment (13), more NHs are striving to better support the personhood of their residents (14). Person-centred care (PCC) can improve the care quality and well-being of NH residents (15). Current literature on the application of PCC in NHs and its association with residents' well-being in Asia is limited. Funded by grants to design and build sustainable person-centric NHs in Singapore, this study examined resident well-being, satisfaction, and the level of PCC in Singapore NHs. We adopted PCC assessments that can be used objectively by $\mathrm{NH}$ staff so that the NHs involved can continue to use these assessments as baseline for care improvement. We also examined the relationship of PCC with resident well-being.

\section{Methods}

This is a cross-sectional study of residents from seven Singapore NHs. Data was collected between December 2016 and February 2019 from residents and care staff. There were 69 NHs in Singapore in 2016. The seven institutions in this study (Supplementary Table 1) were selected in consultation with the national NH planning agency to be representative of local $\mathrm{NHs}$ in terms of resident composition, design typology and year built. These homes offered residential care for individuals requiring assistance in most of their activities of daily living (ADL) or daily nursing procedures.

The residents were selected with proportional stratified random sampling according to their functional status and dementia diagnosis. Following institutional research guidelines, informed consent was obtained from residents with mental capacity to consent to be involved in the study, and from a family member for residents with insufficient capacity. From the sample, an average of 30 residents per NH was randomly selected for Dementia Care Mapping (DCM). Thirty residents with communication ability per NH completed the Resident Satisfaction Survey (RSS). The ability to communicate is defined by being able to give comprehensible responses to the questionnaire. Ethics approval was obtained from National University of Singapore.

\section{Subjects' characteristics}

Subjects' demographics, dementia diagnosis, and functional status were obtained from medical records. Functional status was assessed by the Resident Assessment Form (RAF) used for all NHs (16). It uses nine indicators, including physical, cognitive, and psychological domains to categorize residents: 1:being ambulant and independent in ADLs; 2 :semi-ambulant and semi-independent in ADLs, 3:non-ambulant, wheelchair bound and requiring assistance in ADLs, and 4:bedbound, fully dependent in ADLs or requiring daily nursing care. Categories 3 or 4 is a NH admission criterion. Selected category 2 residents were admitted as their care needs were not met in the community.

\section{Quality of Life}

EQ-5D measures health-related QOL (17), with norm values for Singapore (18). The proxy EQ-5D-5L version used had been validated (19). Direct care staff received training by the research team on EQ-5D, knew the residents well and had been in contact with the residents in the seven days prior to rating. Residents' QOL were rated on a 5-level scale on mobility, selfcare, usual activities, pain/discomfort and anxiety/depression. The health states were converted to individual index QOL scores and utility score calculated from Singapore value set (18, 20).

\section{Well/Ill-being (WIB)}

DCM is grounded in PCC (21). Developed as a tool for care staff, DCM has been adopted (22) as an objective measure of, and tool to improve well-being and care quality (23). Two certified DCM mappers from the local Alzheimer's Disease Association tracked five residents per mapper each time. The residents' actions (Behavioural Category Codes (BCCs)), and Well/Ill Being (WIB) values were recorded at 5-minute intervals. WIB scores were recorded on an 6-point ordinal scale $(+5$ :extremely high level of well-being; +3 :moderate level of well-being; +1: no well-being or ill-being observable; -1:modest level of ill-being; -3:moderate level of ill-being; -5 :extreme distress). Each resident was observed over two two-hour sessions (am and pm during meal/activity times in communal spaces). BCCs were aggregated into those with high and low potentials for well-being. Based on the BCC, length of time in each BCC and Mood and Engagement (ME) values recorded, the overall WIB score was calculated, denoting the affective state of each subject. The effects of care actions on residents were noted as actions that improve well-being [Personal Enhancers (PEs)] or reduce well-being [Personal Detractors (PDs)]; and were classified into 5 Fundamental Needs (Comfort, Attachment, Occupation, Identity, and Inclusion). Rate of PE/PD is the number of PEs/PDs per person-hour mapped (22). 
THE JOURNAL OF NURSING HOME RESEARCH SCIENCESC

Table 1

Demographics of residents

\begin{tabular}{|c|c|c|}
\hline Resident demographics & Quality of Life (EQ-5D-5L Proxy) No. (\%) & Well-Being (DCM) No. (\%) \\
\hline No. of participants & 696 & 207 \\
\hline Mean age, years (SD) & $75.4(12.5)$ & $75.8(12.8)$ \\
\hline \multicolumn{3}{|l|}{ Gender } \\
\hline Female & $362(52.0)$ & $125(60.4)$ \\
\hline Male & $334(48.0)$ & $82(39.6)$ \\
\hline \multicolumn{3}{|l|}{ Ethnicity } \\
\hline Chinese & 547 (78.6) & $164(79.2)$ \\
\hline Indian & $69(9.9)$ & $17(8.2)$ \\
\hline Malay & $67(9.6)$ & 24 (11.6) \\
\hline Eurasian/Others & $13(1.9)$ & $2(1.0)$ \\
\hline \multicolumn{3}{|l|}{ Marital Status } \\
\hline Married & $168(24.1)$ & $56(27.1)$ \\
\hline Single & $250(35.9)$ & $60(29.0)$ \\
\hline Divorced/separated & $69(9.9)$ & $14(6.8)$ \\
\hline Widowed & $198(28.4)$ & $74(35.7)$ \\
\hline Unknown & $11(1.6)$ & $3(1.4)$ \\
\hline \multicolumn{3}{|c|}{ Functional status (RAF category) } \\
\hline Category 2 & $34(4.9)$ & $6(2.9)$ \\
\hline Category 3 & $365(52.4)$ & 117 (56.6) \\
\hline Category 4 & $289(41.5)$ & $84(40.6)$ \\
\hline Unknown & $8(1.2)$ & $0(0.0)$ \\
\hline \multicolumn{3}{|l|}{ Communication ability } \\
\hline Yes & $637(91.5)$ & $207(100.0)$ \\
\hline No & $59(8.48)$ & $0(0.0)$ \\
\hline \multicolumn{3}{|l|}{ Dementia diagnosis } \\
\hline Yes & $26(32.5)$ & $72(34.8)$ \\
\hline No & $470(67.5)$ & $135(65.2)$ \\
\hline
\end{tabular}

\section{Resident Satisfaction}

Residents graded their satisfaction on 5 domains of care: environment, interaction with people, activities, food, and impact on lifestyle and overall. Each domain is graded based on a set of questions pertaining to care. The levels of satisfaction were reported on a scale of 1-5 (1:strong dissatisfaction; 3:neutral; 5:high satisfaction).

\section{Person-Centred Care}

The Person-Directed Dementia Care Assessment Tool (PDDCAT) was developed as a guide for promoting PCC for people with dementia in long-term care settings (24). We adopted PDDCAT as measure and improvement tool for PCC because care staff identifies key strengths and areas for improvement. With re-assessments over time, it facilitates the practice improvement process. Six (staff knowledge and training, problem solving, knowledge and training, environment, care plans and activities) of nine PDDCAT domains with relevance to direct care and can be assessed by NH staff were adopted (186 indicators assessed, Table 4). Each indicator was scored 1-4 (1:item not present; 2:item present but could be improved; 3 :item present in a satisfactory way and considered a strength; 4:item is significant strength that can be used to help implement other practices). Each of six domains were independently assessed by two care staff (trained by research team) in each NH. Any disagreement was resolved during review by a research trainer to achieve a consensus rating. The two research trainers were the Alzheimer's Disease Association DCM mappers who were experienced in using PDDCAT for care improvement. 


\section{EXTENT OF PERSON-CENTRED CARE IN ASIAN NURSING HOMES}

\section{Table 2}

Numbers and proportions reporting levels within EQ-5D dimensions

\begin{tabular}{|c|c|c|c|c|c|}
\hline & $\begin{array}{l}\text { Mobility } \\
\text { n }(\%)\end{array}$ & $\begin{array}{c}\text { Self-care } \\
\text { n }(\%)\end{array}$ & $\begin{array}{c}\text { Usual activities } \\
\text { n (\%) }\end{array}$ & $\begin{array}{c}\text { Pain/ discomfort } \\
\text { n }(\%)\end{array}$ & $\begin{array}{c}\text { Anxiety/ depression } \\
\text { n (\%) }\end{array}$ \\
\hline Level 1 (No problem) & $107(15.7)$ & $110(16.2)$ & $115(17.0)$ & $272(40.1)$ & $219(32.5)$ \\
\hline Level 2 (Slight problem) & $121(17.8)$ & $138(20.3)$ & $136(20.0)$ & $237(34.9)$ & $252(37.4)$ \\
\hline Level 3 (Moderate problem) & $121(17.8)$ & $144(21.1)$ & $164(24.2)$ & $117(17.2)$ & $136(20.2)$ \\
\hline Level 4 (Severe problem) & $115(16.9)$ & $106(15.6)$ & $120(17.7)$ & $46(6.77)$ & $58(8.61$ \\
\hline Level 5 (Extreme problem/ unable to do) & $217(31.9)$ & $183(26.9)$ & $143(21.1)$ & $7(1.0)$ & $9(1.3)$ \\
\hline Total & 681 & 681 & 678 & 679 & 674 \\
\hline
\end{tabular}

Table 3

Profile of Dementia Care Mapping (DCM)

\begin{tabular}{|c|c|c|}
\hline & & $\%$ of time $(n=8619)$ \\
\hline Mean score (SD) & & $1.69(0.98)$ \\
\hline \multicolumn{3}{|l|}{ WIB score } \\
\hline \multirow[t]{2}{*}{ Ill-being } & -5 & 0 \\
\hline & -3 & 0 \\
\hline Neutral & +1 & 48 \\
\hline \multirow[t]{2}{*}{ Well-being } & +3 & 20 \\
\hline & +5 & 9 \\
\hline \multicolumn{3}{|l|}{ Behavioural Category Codes (BCC) } \\
\hline Doing for self & & 8 \\
\hline Expressive & & 1 \\
\hline Intellectual & & 1 \\
\hline Joints & & 2 \\
\hline Leisure & & 13 \\
\hline Religion & & 0 \\
\hline Vocational & & 0 \\
\hline Total BCC with low or no potential & & 39 \\
\hline
\end{tabular}




\section{Statistical analysis}

Statistical analysis was performed using Stata, version 14.0 (StataCorp, College Station, TX). Descriptive statistics were computed for sociodemographic and clinical variables. Results were presented as proportion for categorical variables and mean (SD) for continuous variables. Analysis of covariance was used to compare the mean well-being of the residents (WIB) between the $7 \mathrm{NH}$ with respective to PDDCAT score, with adjustment for age, gender, dementia diagnosis, communication ability and RAF category.

\section{Results}

Study sample comprised 696 residents from 7 NH (Table 1), and resembled Singapore population of Chinese majority. Most (94.0\%) subjects were at least wheelchair-bound and required assistance in most ADLs. Most (91.5\%) could communicate and $32.5 \%$ had dementia diagnosis.

\section{Quality of Life (QoL)}

Mean EQ-5D-5L index was $0.096(\mathrm{SD}=0.45)$. Based on the Singapore value set, the EQ-5D-5L utility score can range from -0.77 to $1.0(1=$ perfect health, $0=$ death, and less than $0=$ health state worse than death). About two-thirds had at least moderate problems in mobility $(66.5 \%)$, self-care $(63.6 \%)$ and usual activities $(63.0 \%)$ (Table 2). Less than one-third had at least moderate problems in the psychological dimensions of pain/ discomfort (25.0\%) and anxiety/depression (30.1\%).

\section{Well/Ill Being (WIB)}

207 residents were mapped over 718.25 hours (8619x5-minutes). Their socio-demographics, functional status and dementia diagnoses were comparable to the main group (Table 2).

Table 3 shows the DCM profile. Mean WIB score of the whole group was $1.69 / 5(\mathrm{SD}=0.98)$, just above the +1 level (no signs of well- or ill-being), with score +1 in $48 \%$ of the observations. This implied that the residents were in a state of neutrality (no overt well- or ill-being) most of the time. A score more than +1 (well-being) was recorded $29 \%$, while a score less than -1 (ill-being) was recorded $6 \%$ of the time.

Top 3 behavioral codes were sleeping (18\%), passively engaged (17\%) and leisure activities (13\%) (Table 3). Other than leisure activities, relatively little time were spent in other activities high potential to improve well-being, e.g. articulation $(8 \%)$, exercise $(2 \%)$, vocational activities (1\%), and religion $(0 \%)$. Overall, behaviors with a high potential for well-being were observed $37 \%$, while those with little/no potential for well-being $39 \%$ of the time.

Supplementary Table 2 shows the PEs and PDs identified in DCM. The rates of PEs and PDs were 0.0021 and 0.0014 , respectively. While care enhancers (warmth, acknowledgement, facilitation) were observed, overall PEs rate was only modestly higher than PDs. The top five detractors (objectification, ignoring, imposition, withholding and infantilization) compromised 4 of the 5 Fundamental Needs. Occupation was most undermined (86 incidences), mostly by objectification (treated with debasing attitude) and imposition of care without consent. Inclusion was next most compromised (46 incidences), mostly by staff ignoring residents (39 incidences).

\section{Resident Satisfaction}

Approximately two-thirds of residents reported being satisfied with care while $60 \%$ agreed with statement "I feel happy" (Supplementary Figure 1). The mean overall satisfaction was $3.43 / 5(\mathrm{SD}=0.83)$. Residents reported moderate satisfaction in environment $(3.25, \mathrm{SD}=0.54)$, food (3.23, $\mathrm{SD}=0.68)$ and activities (3.17, $\mathrm{SD}=0.11)$. They reported least satisfaction with impact on lifestyle $(2.65, \mathrm{SD}=0.73)$ and quality of interaction $(2.97, \mathrm{SD}=0.63)$. The 6 questions with the lowest scores (more than 50\% reported dissatisfaction) were: 1) time in outdoor spaces, 2) interaction with community, 3) ability to maintain same home routine, 4) awareness of happenings outside $\mathrm{NH}, 5$ ) staff informing residents about what is happening and 6) staff asking residents for their preferences (Supplementary Figure 1).

\section{Figure 1}

Box plot of WIB with PDDCAT for each nursing home

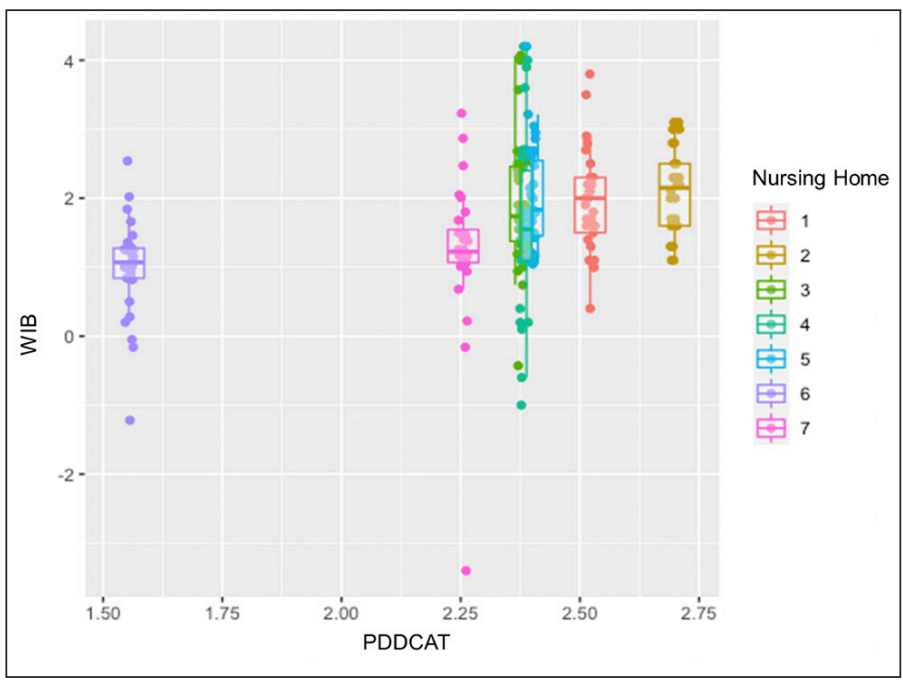

ANOVA, $\mathrm{F}=4.43, \mathrm{p}<0.001$

\section{PCC measured by PDDCAT}

The mean score of the six PCC domains was 2.31/4 $(\mathrm{SD}=0.36)$. Table 4 shows domain scores and component indicators. Environment had the lowest score $(2.10 / 4$, $\mathrm{SD}=0.38)$. Lack of visual cues and personalisation of space were especially deficient. Next lowest was Staff Knowledge and Training $(2.24 / 4, \mathrm{SD}=0.45)$.This was followed by Care Plans (2.33/4, SD=0.51), Language and Communications $(2.36 / 4, \mathrm{SD}=0.45)$, and Problem-Solving Processes for Behavioural Communications $(2.47 / 4, \mathrm{SD}=0.31)$. Even the best 


\section{EXTENT OF PERSON-CENTRED CARE IN ASIAN NURSING HOMES}

performing domain, Activities (2.71/4 $\mathrm{SD}=0.23)$ fell short of the score of 3 (signifies strength). Only Activity Engagement Process (a sub-domain of Activities), scored 3.15/4, SD=0.51, meaning while all the key components of PCC were present, only Activity Engagement Process could be considered a strength.

\section{Table 4}

Domains and indicators of Person-Directed Dementia Care Assessment Tool (PDDCAT)

\begin{tabular}{ll}
\hline Domain/Indicators & Mean (SD) \\
\hline Environment & $2.10(0.38)$ \\
Personalization of space & $1.90(0.42)$ \\
Visual cues & $1.92(0.47)$ \\
Sound & $2.07(0.33)$ \\
Space configuration & $2.08(0.56)$ \\
Lighting colour patterns & $2.20(0.29)$ \\
Ambiance & $2.39(0.41)$ \\
Staff knowledge and training & $2.24(0.45)$ \\
Best practice knowledge and topics & $2.20(0.40)$ \\
Attitudes & $2.22(0.46)$ \\
Training resources and frequency & $2.38(0.66)$ \\
Care plan & $2.33(0.51)$ \\
Content of care plans & $2.05(0.58)$ \\
Use of care plans & $2.16(0.52)$ \\
Assessment information for care plans & $2.49(0.57)$ \\
Establishment of care plans & $2.64(0.56)$ \\
Language and communication & $2.36(0.45)$ \\
Positive titles for staff/ teams / initiatives & $1.86(0.90)$ \\
Negative, generalized labels eliminated & $2.14(0.90)$ \\
Trained to see behavioural communication positively & $2.43(0.53)$ \\
Language convey positive vision & $2.43(0.98)$ \\
Behaviour and language reflect respect and dignity & $2.57(0.79)$ \\
Use of positive and descriptive language & $2.71(0.76)$ \\
Problem solving for behavioural communication & $2.47(0.31)$ \\
Guidelines for medication use for behaviour symptoms & $2.38(0.49)$ \\
Procedure for documenting behaviour & $2.41(0.27)$ \\
Process for understanding individual's behaviour & $2.61(0.49)$ \\
Activities & $2.71(0.23)$ \\
Types of activities & $2.33(0.31)$ \\
Activities practice & $2.50(0.20)$ \\
\hline & $2.60(0.55)$ \\
Activities implementation engagement process & $3.15(0.51)$ \\
\hline
\end{tabular}

WIB scores were significantly different between $7 \mathrm{NH}$ (Figure 1) and were correlated with the level of PCC. $\mathrm{NH}$ with higher level of PCC (by overall mean PDDCAT scores) had higher well-being (WIB) (Spearman coefficient correlation $\mathrm{r}=0.955, \mathrm{p}<0.001$ ). After controlling for age, gender, dementia diagnosis, communication ability and RAF category, the differences between $\mathrm{NH}$ remained significant $(\mathrm{F}=4.43$, $\mathrm{p}<0.001)$.

\section{Discussion}

We examined QoL, well-being, satisfaction, and personcentred care in NH residents. We used both residents' selfreporting and objective observer ratings. Significant findings emerged which may form a baseline for continuous practice improvement and policy initiatives to improve NH residents' well-being in Singapore.

Residents' custodial needs were met in the NHs. Mean DCM WIB score (1.69/5) suggested most residents were relatively comfortable albeit uninvolved. Majority (77\%) of WIB Mood and Engagement states recorded were of neutrality / relative well-being, with a state of mild ill-being observed in only $6 \%$ of overall mapping. From RSS, two-thirds residents were satisfied with overall care and in environment and food. However, their EQ-5D index value of 0.096 is comparable to that of persons with dementia during hospitalization (25). The low QoL by EQ-5D was mainly due to problems with mobility, self-care, and usual activities as most residents (93.9\%) had moderate to severe disabilities based on RAF. In contrast, the domains pain/discomfort and anxiety/depression showed most residents had little problems. However, the extent of psychological distress might have been under-appreciated in the assessment by proxies. Other factors such as dignity, autonomy, and security also contribute to the residents' QoL of NH (25).

Our findings suggest inadequacies in meeting the psychosocial-emotional needs of NH residents. As DCM was performed during activity periods in communal spaces, residents should be most engaged. However, less than $30 \%$ of time was spent being engaged and in a state of well-being. Residents were often in borderline and detached conditions with neither sign of pleasure nor distress ( $48 \%$ of the time). Conceivably, disengagement magnifies apathy, boredom and loneliness which speeds physical, cognitive, and functional deterioration (26). A key component of QoL comprises participation in activities meaningful to the person (27). Hence, the amount of time spent in activities with high potential for well-being is a measure of the care environment's capacity for meaningful engagement. Although 37\% of the residents' time was spent in behaviours with the potential to improve well-being, an equal proportion (39\%) was on activities with low or no potential. Positive caregiving (PEs), focusing on individuality and potential, can improve psychological care in persons with dementia. The theoretical basis of PCC considers sense of personal worth, agency, social confidence and hope as global states of well-being for human (21). In PCC, the rate of PEs should far exceed that of PDs. In this study, the rate of PEs (0.0021) was comparable to the rate of PDs (0.0014). In 


\section{THE JOURNAL OF NURSING HOME RESEARCH SCIENCESC}

addition, a wide range of negative of care practices (PDs) were identified, suggesting room for improvement in PCC.

The shortcomings in addressing residents' psychoemotional were reiterated by RSS findings, more than half were dissatisfied in areas of psycho-emotional needs and autonomy (interaction with community, maintain home routine, awareness of happenings outside $\mathrm{NH}$, staff informing residents about what is happening and considering their preferences). Yet, despite the relatively low level of satisfaction in these areas, most residents reported being contented with overall care. This suggests accommodation of standards and lowering of expectations for personal fulfilment, connectedness, and autonomy in $\mathrm{NH}$ life. These findings are consistent with previous research reporting seniors learnt to cope by lowering life expectations $(28,29)$. This study also demonstrated a clear association between level of PCC and residents' well-being. Instead of consigning to lowering expectations, the residents should be empowered as stakeholders in care planning to achieve person-centred care and higher well-being.

PDDCAT suggested suboptimal level of PCC, pointing to staff training and physical environment as areas for improvement. NHs can consider using DCM as a practice improvement tool in staff training (30). Care can be improved by reviewing the various BCCs and associated ME values; considering the impact of care detractors and enhancers to determine how activities and interactions can be modified to enhance well-being. In addition, $\mathrm{NH}$ must promote staff attitude towards making personhood central to care provision. Care process enhancement needs to be complemented with an enabling environment. Both physical and social environment influence the well-being of $\mathrm{NH}$ residents. In terms of physical environment, there was lack of visual cues to prompt independence (e.g. items for self-initiated activities or labelling to allow identification of areas) or promote selfesteem (e.g. display of individual creations). Opportunities for personalisation of space was limited due to shared rooms, the use of standard furniture and limited personal space. $\mathrm{NHs}$ physical environment should provide adequate personal space, outdoor space, facilitate orientation, offer different activity areas and enough mobility space to promote independence and freedom.

As a first step in research translation, findings were discussed with individual NHs. Two NHs had incorporated their results and implemented DCM for care development. As NH staff adopt DCM, significant challenges remain in PCC implementation (31). Nevertheless, even as the importance of involving residents in decision-making is increasingly recognized, balancing the provision of PCC with pragmatic constraints of shared living environment remain a challenging yet worthwhile pursuit.

Another constraint in our context pertains to direct $\mathrm{NH}$ care provided by foreign workforce. The resulting communication challenges has been identified as a factor for poor QOL (25). Care staff must overcome language and sociocultural differences to better understand and meet residents' needs. Fundamentally, closing the gap between care philosophies and their translation into an actual care environment that is truly resident-directed (32) is a clear priority. This study was conducted before the COVID-19 pandemic and its implications on infection control have become more urgent (33).

\section{Strengths and limitations of study}

Previous studies on residents' QOL in Asian NH $(11,12)$ mainly provided qualitative insights with few quantitative documentations of PCC (34), none that used DCM and other PCC measures. Using data sources that offered perspectives of the residents, direct care staff as well as third-party observers to provide a holistic view on PCC and well-being, ours is the most comprehensive Asian study on the lived experience of $\mathrm{NH}$ residents.

The PDDCAT had been developed as a person centric care assessment and improvement tool. It was selected as it involved comprehensive and objective assessment by NH staff as PCC measurement and improvement tool. However, as with many PCC measures, it needs further validation (35).

The selection of varied types of $\mathrm{NHs}$ was meant to provide a large and representative sample of the local $\mathrm{NH}$ population. However, the potential for selection bias cannot be excluded and limits generalisability. The DCM and PDDCAT are developed for persons with dementia but only a third of our subjects (likely underestimate) had formal dementia diagnosis. Nevertheless, these measures have been demonstrated to be useful in persons with or without dementia $(32,36)$. The effectiveness of DCM and PDDCAT for quality improvement need further study.

\section{Conclusion and implications}

Higher level of PCC is associated with better resident wellbeing. Beyond their physical and custodial needs, the residents' psychosocial needs can be better fulfilled. The areas of PCC identified for improvement were related to environment and staff knowledge and training. These findings inform resident care planning, policy development, and future research to support NHs in their endeavour to move towards more holistic and PCC.

Funding: This research is supported by the National Research Foundation and Ministry of National Development, Singapore under the L2 NIC Award No. L2NICTDF1-2017-5. Any opinions, findings and conclusions or recommendations expressed in this material are those of the author(s) and do not reflect the views of National Research Foundation, Singapore and Ministry of National Development, Singapore. It also received funding from a private donation to Saw Swee Hock School of Public Health, National University of Singapore. The sponsors had no role in the design and conduct of the study; in the collection, analysis, and interpretation of the data; in the preparation of the manuscript; or in the review or approval of the manuscript.

Acknowledgements: We acknowledge the contribution of the School of Design and Environment, National University of Singapore. We are also grateful for the cooperation of the staff, families and residents of the participating nursing homes, Carol Fusech and Koh Hwan Jing from ADA for conducting DCM and PDDCAT training, and Ms Chua Xin Ying who helped to coordinate the study set up. 


\section{EXTENT OF PERSON-CENTRED CARE IN ASIAN NURSING HOMES}

Conflict of interest: Chee Wee Tew declares no conflict of interest. Siew Pei Ong declares no conflict of interest. Philip Lin Kiat Yap declares no conflict of interest. Amber Yew Chen Lim declares no conflict of interest. Nan Luo declares no conflict of interest. Gerald Choon Huat Koh declares no conflict of interest. Tze Pin Ng declares no conflict of interest. Shiou Liang Wee declares no conflict of interest.

Ethical standards: Ethics approval was obtained from the National University of Singapore (S-18-078). Informed consent to participate in the study were obtained from residents who were able to make decisions, and from a family member for residents with insufficient capacity.

\section{References}

1. United Nations ESCAP, Social Development Division. 2016 Population data sheet. 2016. https://www.unescap.org/resources/2016-escap-population-data-sheet. Accessed 6 December 2019.

2. National Population and Talent Dividion, Strategy Group, Prime Minister's Office, Singapore. Singapore: a super-aged country? https:/www.population.sg/articles/ singapore-a-superaged-country. Accessed 20 May 2020.

3. Tew CW, Tan LF, Luo N, Ng WY, Yap P. Why family caregivers choose to institutionalize a loved one with dementia: a Singapore perspective. Dement Geriat Cogn Disord 2010;30:509-516.

4. Singapore, Ministry of Health. Healthcare Master Plan 2020. 2012. http://www. nationalplanningcycles.org/sites/default/files/planning_cycle_repository/singapore/ singapore_healthcare_masterplan_2020.pdf. Accessed 10 February 2020.

5. The Gerontological Society of America. 2018. Longevity economics: leveraging the advantages of an aging society. https://www.geron.org/images/gsa/documents/gsalongevity-economics-2018.pdf. Accessed 12 February 2020.

6. Singapore, Ministry of Health. 2019. Bed in inpatient facilities and places in nonresidential long-term care facilities. https://www.moh.gov.sg/resourcesstatistics/ singapore-health-facts/beds-in-inpatient-facilities-and-places-in-non-residential-longterm-care-facilities. Accessed 12 February 2020.

7. World Health Organisation. 2015. World report on ageing and health. https:// apps.who.int/iris/bitstream/handle/10665/186463/9789240694811_eng. pdf; jsessionid=CBBC222FAD80DCAB5A2F363DA6F8CB01 ? sequence $=1$. Accessed 12 February 2020

8. Wong GH, Pang WS, Yap P. A paradigm shift in regulating and running nursing homes in Singapore. J Am Med Dir Assoc 2014;15:440-444.

9. Olsen C, Pedersen I, Bergland A, et al. Differences in quality of life in homedwelling persons and nursing home residents with dementia - a cross-sectional study BMC Geriatr 2016;16:137.

10. Wang P, Yap P, Koh G, et al. Quality of life and related factors of nursing home residents in Singapore. Health Qual Life Outcomes 2016;14:112.

11. Chang SJ. Lived experiences of nursing home residents in Korea. Asian Nurs Res (Korean Soc Nurs Sci) 2013;7:83-90.

12. Tsai HH, Tsai YF. A temporary home to nurture health: lived experiences of older nursing home residents in Taiwan. J Clin Nurs. 2008;17:1915-1922.

13. Vaismoradi M, Wang IL, Turunen H, Bondas T. Older people's experiences of care in nursing homes: a meta-synthesis. Int Nurs Rev 2016;63:111-121.

14. Milte R, Shulver W, Killington M, Bradley C, Ratcliffe J, Crotty M. Quality in residential care from the perspective of people living with dementia: the importance of personhood. Arch Gerontol Geriatr.2016;63:9-17.

15. Poey JL, Hermer L, Cornelison L, et al. Does person-centered care improve residents' satisfaction with nursing home quality? J Am Med Dir Assoc. 2017;18:974-979.
16. Lim CH, Ng JM. Mobilising social care for the family physicians. SFP 2015;41:3245

17. EuroQol. EQ-5D. http://www.euroqol.org/. Accessed 12 October 2019.

18. Luo N, Wang P, Thumboo J, Lim YW, Vrijhoef HJ. Valuation of EQ-5D-3L health states in Singapore: modeling of time trade-off values for 80 empirically observed health states. Pharmacoeconomics 2014;32:495-507.

19. Toh HJ, Yap P, Wee SL, Koh G, Luo N. Feasibility and validity of EQ-5D-5L proxy by nurses in measuring health-related quality of life of nursing home residents. Qual Life Res 2020. https://doi.org/10.1007/s11136-020-02673-5

20. van Hout B, Janssen MF, Feng YS, et al. Interim scoring for the EQ-5D-5L: mapping the EQ-5D-5L to EQ-5D-3L value sets. Value Health 2012;15:708-715.

21. Kitwood T, Bredin K. Towards a theory of dementia care: personhood and wellbeing. Ageing Soc 1992;12:269-287.

22. Brooker DJ, Surr C. Dementia Care Mapping (DCM): initial validation of DCM 8 in UK field trials. Int J Geriatr Psychiatry 2006;21:1018-25.

23. Sloane PD, Brooker D, Cohen L, et al. Dementia care mapping as a research tool. J Geriatr Psychiatry 2007;22:580-589.

24. The Wisconsin Department of Health and Family Services Bureau of Aging and Disability Resources. Person-Directed Dementia Care Assessment Tool. https:/ www.dhs.wisconsin.gov/publications/p2/p20084.pdf. Accessed 5 May 2019.

25. Tay FHE, Thompson CL, Nieh CM, Nieh CC, Koh HM, Tan JJC, et al. Personcentered care for older people with dementia in the acute hospital. Alzheimers Dement. 2018;4:19-27.

26. Cohen-Mansfield J, Dakheel-Ali M, Marx MS. Engagement in persons with dementia: the concept and its measurement. Am J Geriatr Psychiatry 2009;17:299 307.

27. Phinney A, Chaudhury H, O'Connor DL. Doing as much as I can do: the meaning of activity for people with dementia. Aging Ment Health 2007;11:384-93.

28. Hellberg I, Augustsson V, Hellström Muhli U. Seniors' experiences of living in special housing accommodation. Int J Qual Stud Health Well-being 2011;6:10.3402/ qhw.v6i1.5894.

29. Wikström BM. Seniors' experiences of congregate housing in Sweden. Creat Nurs 2010;16:87-94

30. Surr CA, Griffiths AW, Kelley R. Implementing Dementia Care Mapping as a practice development tool in dementia care services: a systematic review. Clin Interv Aging 2018;13:165-177

31. Innes A, Surr C. Measuring the well-being of people with dementia living in formal care settings: the use of Dementia Care Mapping. Aging and Mental Health 2001;5:258-268

32. Kehyayan V, Hirdes JP, Tyas SL, Stolee P. Resident's self-reported quality of life in long-term care facilities in Canada. Can J Aging 2015;34:149-164

33. Wee SL, Yap LKP. Timely lessons from a pandemic on the benefits of person centric care in long term care facilities. J Frailty and Aging. 2020 May 22: 1-2. doi: 10.14283/jfa.2020.28. Epub ahead of print. PMID: 32588025

34. Chan HY, Pang SM. Quality of life concerns and end-of-life care preferences of aged persons in long-term care facilities. J Clin Nurs 2007;16:2158-2166.

35. Martínez T, Suárez-Álvarez J and Yanguas J. Instruments for assessing person centered care in gerontology. Psicothema 2016;28; 114-121.

36. Fossey J, Lee L, Ballard C. Dementia Care Mapping as a research tool for measuring quality of life in care settings: psychometric properties. Int J Geriatr Psychiatry 2002;17:1064-1070. 